\title{
The role of routine flexible sigmoidoscopy in patients presenting with fistula-in-ano: an observational study
}

\author{
Ruvindu Hasamal Waidyasekera, Umesh Jayarajah and Dharmabandhu Nandadeva Samarasekera*
}

\begin{abstract}
Objective: Flexible sigmoidoscopy is useful to look for an underlying aetiology in fistula-in-ano. This study was aimed to assess the yield of routine flexible sigmoidoscopy in patients presenting with fistula-in-ano. A retrospective analysis of 159 consecutive patients with fistula-in-ano who underwent routine flexible sigmoidoscopy was performed. Sigmoidoscopy findings were recorded on a standard uniform format using a computer database. Those with a known aetiology were excluded.

Results: The median age was 39 (range: $14-74)$ years and the majority were males ( $n=128,80.5 \%)$. Forty-nine patients (30.8\%) presented with a recurrent fistula-in-ano. On flexible sigmoidoscopy, internal opening was seen in only 23 patients (14.4\%). Furthermore, incidental findings of haemorrhoids $(n=5,3.1 \%)$ and polyps $(n=7,4.4 \%)$ were found. One patient (0.6\%) had a healed anal fissure, 5 patients (3.1\%) had inflamed mucosa and 2 patients (1.3\%) had ulcers. Only two patients with inflamed mucosa were diagnosed to have Crohn's disease on histology. Therefore, flexible sigmoidoscopy was not helpful in the majority to locate the internal opening. Only two patients had evidence of an underlying aetiology, which was Crohn's disease. However, they had recurrent complex fistulae and other associated symptoms. Therefore, flexible sigmoidoscopy may be reserved for selected group of patients with symptoms of an underlying aetiology.
\end{abstract}

Keywords: Anal fistula, Fistula-in-ano, Flexible sigmoidoscopy, Yield

\section{Introduction}

Although the majority of anal fistulae are cryptoglandular, in some, an underlying aetiology such as inflammatory bowel disease (i.e. Crohn's disease and ulcerative colitis), diverticulitis, tuberculosis and cancer may be present [1]. Accurately determining the anatomy of the fistula and any underlying condition prior to treatment helps to achieve cure and minimises recurrences [2-4].

Prior to definitive treatment, flexible sigmoidoscopies are performed routinely in some units for patients with fistula-in-ano to detect an underlying aetiology. However,

*Correspondence: samarasekera58@yahoo.co.uk Department of Surgery, Faculty of Medicine, University of Colombo, P.O. Box 271, Kynsey Road, Colombo 8, Western Province, Sri Lanka routine flexible sigmoidoscopy may result in higher cost, especially in a setting with limited resources and subjects patients to discomfort and sometimes complications due to endoscopy $[5,6]$.

Therefore, the aim of our study was to evaluate the yield of routine flexible sigmoidoscopy in patients presenting with fistula-in-ano.

\section{Main text \\ Materials and methods}

This is a retrospective analysis of 159 consecutive patients who presented to the University Surgical Unit of National Hospital of Sri Lanka, with a fistula-in-ano between January 2014 and September 2018. Ethical approval was obtained from Ethical Review Committee 
of National of Sri Lanka to conduct the study. All patients gave informed written consent to participate in this study. All patients were evaluated with a rectal examination, flexible sigmoidoscopy and examination under anaesthesia. Those with a diagnosed underlying aetiology such as Crohn's disease, diverticulitis and colorectal cancer and presented with a fistula-in-ano as a complication were excluded from the study.

All the flexible sigmoidoscopy procedures were carried out by a consultant colorectal surgeon or a trainee under supervision. A phosphate enema was given $30 \mathrm{~min}$ before flexible.

Sigmoidoscopy in all patients. Patients were positioned in the left lateral position. The procedure was done with a standard $60-\mathrm{cm}$ fibre optic flexible sigmoidoscope. At the end of the procedure, examination of the anal canl was performed using retroflexion and proctoscopy. Details related to the procedure such the extent of the bowel visualised, findings, quality of preparation and patient details were recorded in a computer based database. Analysed data were expressed in terms of frequencies and percentages.

\section{Results}

A total of 159 patients were included in the analysis. The majority were males 128 (80.5\%). Median age was 39 (range: 14-74) years. Forty-nine (30.8\%) patients presented with recurrent fistulae. Twenty-five patients (15.72\%) presented with additional symptoms other than perianal discharge such as rectal bleeding $(\mathrm{n}=2$, $1.25 \%)$, constipation $(\mathrm{n}=4,2.51 \%)$ and lump at the anus $(\mathrm{n}=6,3.77 \%)$. The majority were trans-sphincteric tracts $(\mathrm{n}=84,52.8 \%)$ followed by inter-sphincteric $(\mathrm{n}=43$, $27.0 \%)$, superficial $(\mathrm{n}=16,10.1 \%)$ and supra-sphincteric $(\mathrm{n}=7,4.4 \%)$ tracts (Table 1$)$.

Visualization was done up to the splenic flexure in the majority $(n=129,81.1 \%)$. In ten patients, $(6.3 \%)$ colon was visualised beyond the splenic flexure, in 13 patients (8.1\%) colon was visualised up to the descending colon and in 7 patients $(4.4 \%)$ colon could not be visualised beyond the sigmoid colon. In 8 patients (5.03\%) there was poor bowel preparation and in 1 patient, the procedure was abandoned due to excessive pain.

Sigmoidoscopy findings of anus, rectum, sigmoid colon and the descending colon were evaluated. Internal opening of the fistula was only seen in 23 patients (14.4\%), 2 of which were seen in the rectum. Furthermore incidental findings of haemorrhoids $(\mathrm{n}=5,3.1 \%)$ and polyps $(\mathrm{n}=7,4.4 \%)$ were found. One patient $(0.6 \%)$ had a healed anal fissure, 5 patients (3.1\%) had inflamed mucosa and 2 patients (1.3\%) had ulcers (Table 2). A total of 139 patients $(87.4 \%)$ had normal studies on flexible sigmoidoscopy. Of the five patients with inflamed mucosa, 2
Table 1 Demographic characteristics and types of fistula

\begin{tabular}{|c|c|c|}
\hline & $\mathbf{N}$ & $\%$ \\
\hline Age in years (Mean $\pm S D$ ) & $40 \pm S D 13$ & \\
\hline \multicolumn{3}{|l|}{ Gender } \\
\hline Male & 128 & 80.5 \\
\hline Female & 31 & 19.5 \\
\hline \multicolumn{3}{|l|}{ Recurrent fistula } \\
\hline Yes & 49 & 30.8 \\
\hline No & 110 & 69.2 \\
\hline \multicolumn{3}{|l|}{ Type of frimary fract } \\
\hline Superficial & 16 & 10.1 \\
\hline Inter-sphincteric & 43 & 27.0 \\
\hline Trans-sphincteric & 84 & 52.8 \\
\hline Supra-sphincteric & 7 & 4.4 \\
\hline Extra-sphincteric & 1 & 0.6 \\
\hline Horse shoe & 1 & 0.6 \\
\hline Multiple tracts & 1 & 0.6 \\
\hline Not classified & 6 & 3.8 \\
\hline \multicolumn{3}{|l|}{ Number of internal openings } \\
\hline 1 & 155 & 97.5 \\
\hline 2 & 4 & 2.5 \\
\hline \multicolumn{3}{|l|}{ Level of internal opening } \\
\hline Below the dentate line & 68 & 42.8 \\
\hline At the dentate line & 67 & 42.1 \\
\hline Above the dentate line & 7 & 4.4 \\
\hline Rectum & 6 & 3.8 \\
\hline Not classified & 11 & 6.9 \\
\hline \multicolumn{3}{|l|}{ Horse shoeing } \\
\hline Inter-sphincteric & 4 & 2.5 \\
\hline Infra-levator (in ischiorectal fossa) & 3 & 1.9 \\
\hline Absent & 152 & 95.6 \\
\hline \multicolumn{3}{|l|}{ Abscess } \\
\hline Inter-sphincteric & 8 & 5.0 \\
\hline Infra-levator & 6 & 3.8 \\
\hline Supra-levator & 1 & 0.6 \\
\hline Absent & 144 & 90.6 \\
\hline \multicolumn{3}{|l|}{ Sphincter defects } \\
\hline Present & 34 & 21.4 \\
\hline Absent & 125 & 78.6 \\
\hline
\end{tabular}

were found to have histological evidence of Crohn's disease while others had unremarkable histological findings. Patients with polyps and ulcers were benign and there was no evidence to suggest an underlying aetiology for fistula-in-ano.

\section{Discussion}

Fistula-in-ano with an underlying aetiology is challenging to manage and associated with high risk of recurrence. Repeated surgeries may lead to incontinence and reduced 
Table 2 Breakdown of flexible sigmoidoscopy findings

\begin{tabular}{lllll}
\hline & Anus & Rectum & Sigmoid colon & Descending colon \\
\hline Normal & $130(81.8 \%)$ & $147(92.5 \%)$ & $152(95.6 \%)$ & $145(91.2 \%)$ \\
Internal opening of fistula & $21(13.2 \%)$ & $2(1.3 \%)$ & - & - \\
Anal fissure & $1(0.6 \%)$ & - & - & - \\
Haemorrhoids & $5(3.1 \%)$ & - & - & - \\
Polyp & $1(0.6 \%)$ & $3(1.9 \%)$ & $1(0.6 \%)$ & $2(1.3 \%)$ \\
Inflamed mucosa & - & $5(3.1 \%)$ & $1(0.6 \%)$ & $2(1.3 \%)$ \\
Ulcer & - & $1(0.6 \%)$ & $2(1.3 \%)$ & - \\
Not visualized & - & - & $10(6.3 \%)$ \\
\hline
\end{tabular}

quality of life $[7,8]$. Flexible sigmoidoscopy is performed for a number of anorectal symptoms for confirmation of diagnosis and exclusion of other underlying causes. Similarly, routine flexible sigmoidoscopy is performed in some units for evaluation of an underlying aetiology in fistula-in-ano. However, there is scarcity of data assessing the effectiveness of flexible sigmoidoscopy in detection of an underlying aetiology in fistula-in-ano. Performing unnecessary routine procedures subject patients to discomfort, risk of complications of endoscopy and may escalate cost on patient care especially in a resource limited setting [6].

The primary focus of this study was to assess the ability to diagnose an underlying aetiology with routine flexible sigmoidoscopy. The majority $(n=139,87.4 \%)$ had no detectable abnormalities on flexible sigmoidoscopy while others had incidental findings. There were 5 patients who were found to have inflamed mucosa suspected of Crohn's disease and only 2 patients were later diagnosed to have Crohn's disease through histology while in the others histology was unremarkable. The two patients diagnosed to have Crohn's disease presented with recurrent complex fistulae and other associated symptoms such as loose stools and abdominal pain. There is increasing prevalence of inflammatory bowel disease in the region $[9,10]$. Therefore, excluding such underlying cause is important for the management.

Histological assessment of those with polyps and ulcers revealed benign findings. One patient presented with an anal fissure along with a fistula. The anal fissure was initially treated prior to attempting a flexible sigmoidoscopy and further follow up was unremarkable with no recurrence of symptoms or evidence of Crohn's disease. Therefore, based on our findings, flexible sigmoidoscopy may be reserved for a selected group of patients with recurrent complex fistulae and associated symptoms of an underlying aetiology.

Flexible sigmoidoscopy was not useful in detecting internal opening in the majority. Only 23 (14.4\%) internal openings were seen on flexible sigmoidoscopy, 2 of which were found in the rectum. However, examination under anaesthesia was done in all patients revealed an internal opening confirming a fistula. Multiple internal openings were present in 4 patients $(2.5 \%)$ which however were not visualised on flexible sigmoidoscopy.

\section{Conclusion}

This study revealed that flexible sigmoidoscopy was not helpful in finding the underlying aetiology in the majority of patients presenting with fistula-in-ano. The majority of flexible sigmoidoscopies were normal and most of the findings were incidental. Only two patients had evidence of an underlying aetiology which was Crohn's disease. However, they had recurrent complex fistulae and other associated symptoms. Therefore, flexible sigmoidoscopy may be reserved for a selected group of patients with recurrent complex fistulae and associated symptoms of an underlying aetiology.

\section{Limitations}

This is a retrospective study with a small sample size. However, the findings were systematically recorded in a computer database allowing accurate and easy retrieval of data.

\section{Acknowledgements \\ None.}

\section{Authors' contributions}

RHW designed the tables; collected, analysed, and interpreted data; and wrote the article. UJ formulated the concept and design of study, acquisition of data and analysis and drafting the article. DNS contributed to design and concept of study, revising it critically for important intellectual content and approval of the final version to be published. All authors read and approved the final manuscript.

\section{Funding \\ None declared.}

\section{Availability of data and materials}

The datasets generated and analysed during the current study are available from the corresponding author on reasonable request. 


\section{Ethics approval and consent to participate}

Ethical approval was obtained from Ethical Review Committee of National of Sri Lanka to conduct the study. All patients gave informed written consent to participate in this study.

\section{Consent for publication}

Not obtained.

\section{Competing Interests}

The authors declare that they have no competing interests.

Received: 9 March 2020 Accepted: 7 April 2020

Published online: 16 April 2020

\section{References}

1. Parks A. Pathogenesis and treatment of fistula-in-ano. BMJ. 1961;1(5224):463.

2. Londono-Schimmer E, Garcia-Duperly R, Nicholls R, Ritchie J, Hawley P, Thomson J. Overlapping anal sphincter repair for faecal incontinence due to sphincter trauma: five year follow-up functional results. Int J Colorectal Dis. 1994;9(2):110-3.

3. Almeida IS, Jayarajah U, Wickramasinghe DP, Samarasekera DN. Value of three-dimensional endoanal ultrasound scan (3D-EAUS) in preoperative assessment of fistula-in-ano. BMC Res Notes. 2019;12(1):66.
4. Jayarajah U, Samarasekera D. Predictive accuracy of Goodsall's rule for fistula-in-ano. Ceylon Med J. 2017;62(2):97-9.

5. Jayarajah U, De Silva M, Samarasekera D. The role of flexible sigmoidoscopy in the evaluation of patients presenting with a lump at anus. Sri Lanka J Surg. 2017:35(1):1-5.

6. Jayarajah U, de Silva V, Samarasekera D. The role of flexible sigmoidoscopy in the evaluation of isolated rectal bleeding. Ceylon Med J. 2017;62(4):250-52.

7. Jayarajah U, Wickramasinghe DP, Samarasekera DN. Anal incontinence and quality of life following operative treatment of simple cryptoglandular fistula-in-ano: a prospective study. BMC Res Notes. 2017;10(1):572.

8. Banagala S, Jayarajah U, Almeida I, Samarasekera DN. Efficacy of irrigation tubes in the management of para rectal cavities associated with complex fistula-in-ano. BMC Surg. 2018;18(1):95.

9. Jayarajah U, Navarathne N, Samarasekera N, Subramaniam N, de Zoysa IM, Seneviratne SL. Epidemiology, pathogenesis and treatment of ulcerative colitis in South Asia. Int J Progres Sci Technol. 2017;6(1):205-12.

10. Jayarajah U, Navarathne N, de Zoysa I, Subramaniam N, Samarasekera N Seneviratne SL. Crohn's disease in South Asia. Int J Progres Sci Technol. 2017:6(1):193-204.

\section{Publisher's Note}

Springer Nature remains neutral with regard to jurisdictional claims in published maps and institutional affiliations.
Ready to submit your research? Choose BMC and benefit from:

- fast, convenient online submission

- thorough peer review by experienced researchers in your field

- rapid publication on acceptance

- support for research data, including large and complex data types

- gold Open Access which fosters wider collaboration and increased citations

- maximum visibility for your research: over $100 \mathrm{M}$ website views per year

At BMC, research is always in progress.

Learn more biomedcentral.com/submissions 